\title{
Práticas Favorecedoras ao Contexto Escolar: Discutindo Formação e Atuação de Psicólogos Escolares
}

\author{
Lorena de Almeida Cavalcante ${ }^{1}$ \\ Fabiola de Sousa Braz, Aquino ${ }^{2}$ \\ ${ }^{1}$ Universidade de Brasília, Brasilia, DF \\ ${ }^{2}$ Universidade Federal da Paraíba, João Pessoa, PB
}

\begin{abstract}
Resumo
A presente pesquisa objetivou identificar, por meio de realização e análise de entrevistas junto a 55 psicólogos escolares, concepções acerca de práticas favorecedoras de aprendizagem e desenvolvimento no contexto escolar. A maioria dos participantes tinha concluído o curso há mais de 20 anos, não apresentava formação em Psicologia Escolar, tampouco havia realizado estágio supervisionado e pós-graduações no âmbito da referida área. As intervenções dos profissionais entrevistados se concentravam nos alunos, pais e agentes escolares, embora muitas vezes a prática com os referidos grupos ocorresse de forma isolada. Para os participantes, as práticas favorecedoras englobavam, principalmente, intervir com os alunos, seguidos de intervir nas relações, com os pais, no âmbito pedagógico e com os agentes escolares. Os resultados indicam a relevância das formações inicial e continuada em Psicologia Escolar como contextos para desenvolver competências específicas do psicólogo escolar e forjar o compromisso social com a promoção de aprendizagem e desenvolvimento.

Palavras-chave: psicologia escolar, formação profissional, práticas favorecedoras
\end{abstract}

\section{Favoring Practices to School Context: Discussing School Psychologist's Academic Education and Performance}

\begin{abstract}
This research aimed to identify, by conducting and analyzing interviews with 55 school psychologists, conceptions about favoring practices to learning and development at school context. Most professionals concluded Psychology course for more than 20 years ago, did not have graduation focused on School Psychology neither had realized supervisioned internship and post graduations in this area. The intervention of the interviewed professionals focused on students, parents and school professionals, although often the practice with such groups occur isolatedly. For participants, the favoring practices included mainly to intervene with students, followed by to intervene with relations, with parents, in the pedagogical framework and with school professionals. The results indicate the relevance of initial and continued formations in School Psychology as contexts to develop specific school psychologist's competences and to forge social commitment with the promotion of learning and development. Keywords: school psychology; professional formation; favoring practices
\end{abstract}

\section{Prácticas Favorecedoras al Contexto Escolar: Discutiendo Formación y Actuación de Psicólogos Escolares}

\begin{abstract}
Resumen
Esta investigación tuvo como objetivo identificar, por medio de realización y análisis de entrevistas con 55 psicólogos escolares, concepciones sobre prácticas favorecedoras de aprendizaje y desarrollo en el contexto escolar. La mayoría de los profesionales hubiera concluido el curso hace más de 20 años, no tenía formación en Psicología Escolar y no había realizado práctica supervisada y postgrados en el área. La intervención de los entrevistados se centró en estudiantes, padres y agentes escolares, aunque muchas veces la práctica con esos grupos ocurriera aisladamente. Para los participantes, las prácticas favorecedoras engloban principalmente intervenir con los estudiantes, seguida de intervenir en las relaciones, con los padres, en el ámbito pedagógico y con los agentes escolares. Los resultados indican la relevancia de las formaciones inicial y continuada en Psicología Escolar como contextos para desarrollar competencias específicas de lo psicólogo escolar y forjar el compromiso social con la promoción de aprendizaje y desarrollo.

Palabras-clave: psicología escolar; formación profesional; prácticas favorecedoras
\end{abstract}

\section{Introdução}

Estudiosos da Psicologia Escolar (Guzzo, 2000, 2016; Marinho-Araujo \& Almeida, 2014; Martínez, 2010; Neves, 2009, 2010, 2011; Souza, Petroni, \& Dugnani, 2011; Souza, Petroni, Dugnani, Barbosa, \& Andrada, 2014) relatam que, nos primórdios da área, predominavam práticas remediativas e adaptacionistas, fortemente atreladas ao atendimento de crianças e jovens que supostamente apresentavam problemas de desenvolvimento e aprendizagem (Antunes, 2011; Cruces, 2010; Guzzo, 2011). Contudo, entre o fim da década de 1970 e início da década seguinte, teve início o período conhecido como a década da denúncia (Barbosa, 2012), cuja grande expoente foi Maria Helena Souza Patto (1997), que questionou a que e a quem a 
Psicologia Escolar servia. Foram formuladas críticas contundentes a práticas psicológicas que não favoreciam os processos de aprendizagem e desenvolvimento, uma vez que, compreendendo o fracasso escolar a partir de hipotéticos déficits psicológicos, biológicos ou socioculturais, os psicólogos concentravam-se na avaliação e no diagnóstico de hipotéticos problemas de aprendizagem e distúrbios comportamentais (Guzzo, 2016; Souza, 2011).

Argumentos de pesquisadores da área (Guzzo, 2002, 2008, 2010, 2011; Marinho-Araujo \& Neves, 2007; Martínez, 2010; Patto, 1981) convergem para a ideia de que esse tipo de atuação, marcadamente clínica, nos contextos escolares tinha suas bases na formação disponibilizada até então pelos cursos de graduação em Psicologia no Brasil. Diante disso, e como resultado de críticas a esse tipo de atuação, estudiosos da Psicologia Escolar passaram a defender a reformulação dos cursos de Psicologia, de modo que passassem a contemplar, dentre outros aspectos, momentos de estágio em Psicologia Escolar, problematizações sobre as demandas reais do contexto escolar educacional e leituras globais e contextualizadas sobre os processos de desenvolvimento e aprendizagem (Barbosa, 2008; Guzzo, 2010, 2011; Maluf \& Cruces, 2008; Marinho-Araujo \& Almeida, 2014; Marinho-Araujo \& Neves, 2007; Mendes, 2011; Patto, 1997).

Como parte das estratégias para alterar esse cenário, foram homologadas as Diretrizes Curriculares Nacionais para os Cursos de Graduação em Psicologia (Brasil, 2004, 2011). As diretrizes são consideradas um avanço em relação ao currículo mínimo que vigorava até então (Guzzo, 2011; Marinho-Araujo \& Almeida, 2014; Marinho-Araujo \& Neves, 2007; Nunes, Alves, Ramalho, \& Braz Aquino, 2014) porque, entre outros aspectos, estabeleceram a reformulação dos cursos de graduação em Psicologia do país segundo princípios e fundamentos norteadores amplamente debatidos entre estudiosos e profissionais da área. Em consequência, geraram novos desafios à formação em Psicologia, especialmente na área Escolar, no sentido de oportunizar uma formação ampla, capaz de promover o desenvolvimento das habilidades e competências requeridas aos mais diversos âmbitos de atuação profissional (Nunes et al., 2014).

No ano de 2018, com o objetivo de repensar a formação de psicólogos por meio de um novo processo nacional de revisão das diretrizes, o Conselho Federal de Psicologia aprovou o documento intitulado "Ano da Formação em Psicologia: Revisão das
Diretrizes Curriculares Nacionais para os Cursos de Graduação em Psicologia”. Nele, propõe-se discutir referências, reformulações e novas contribuições para a formação na área, de modo a subsidiar práticas profissionais que respondam às demandas das sociedades brasileira e latino-americana.

Frente ao exposto, depreende-se que, por meio da ampliação da dimensão formativa e da mobilização de saberes científicos e práticos, são favorecidas: (a) a construção e a reconstrução de competências; (b) a constituição de um perfil profissional competente, atuante, participativo e socialmente comprometido; (c) a transformação de concepções cristalizadas sobre o desenvolvimento humano e a aprendizagem; (d) a mudança de paradigmas, especialmente, do fracasso escolar para o sucesso escolar, da doença para a promoção da saúde e do bem-estar subjetivo (Guzzo, 2011; Marinho-Araujo \& Almeida, 2014). Essa confluência entre teoria e prática é essencial para o delineamento de novas formas de atuação em Psicologia Escolar (Barbosa \& Marinho-Araujo, 2010; Guzzo, Mezzalira, Moreira, Tizzei, \& Neto, 2010; Maluf e Cruces, 2008; Marinho-Araujo \& Almeida, 2014) e contribui para que a escola cumpra sua função social de favorecer, por meio da socialização do saber, processos de humanização (Nunes et al., 2014).

No cenário contemporâneo, considera-se que a Psicologia Escolar brasileira vive nova fase. Observase o desenvolvimento de pesquisas e intervenções que enfatizam a formação do psicólogo para lidar com demandas escolares e há também a proposição de modelos de atuação pautados na ressignificação de concepções e práticas, segundo uma perspectiva preventiva, institucional, relacional e socialmente comprometida (Antunes, 2011, Barbosa \& Marinho -Araujo, 2010; Marinho-Araujo, 2010; Martínez, 2010; Oliveira \& Marinho-Araujo, 2009). Em face dessa mudança de paradigmas, a referida área vem sendo compreendida como campo de pesquisa e intervenção em que o psicólogo deve mediar processos de aprendizagem e desenvolvimento (Oliveira \& Marinho-Araujo, 2009). A esse respeito, Guzzo (2008a, 2008b, 2011) enfatiza que a relevância da presença do psicólogo em instituições escolares encontra-se nas seguintes possibilidades que tem esse profissional: (a) investigar e acompanhar de perto as demandas institucionais; (b) trabalhar em conjunto com os demais agentes escolares; (c) desenvolver um trabalho preventivo; (d) favorecer e potencializar processos de desenvolvimento e aprendizagem; (e) promover 
ações conscientes, competentes, comprometidas e transformadoras.

No presente estudo, entende-se que o potencial de ação desse profissional é reduzido ou anulado quando, embora inserido na instituição escolar, não desenvolve práticas intencionais e conscientes no âmbito das competências esperadas do psicólogo escolar educacional (Guzzo, 2011, 2016). Nesse sentido, afirma-se a relevância do psicólogo escolar na promoção de práticas preventivas e intencionalmente planejadas visando favorecer e potencializar processos de aprendizagem e desenvolvimento de crianças, jovens e adultos no contexto escolar, ou seja, de todos os segmentos da comunidade escolar, aqui incluído o próprio psicólogo escolar.

Desse modo, são práticas favorecedoras de aprendizagem e desenvolvimento aquelas que, dentre outros aspectos: (a) asseguram a qualidade e a efetividade das mediações desenvolvidas ao longo do processo de ensino e aprendizagem; (b) promovem espaços e processos de reflexão crítica, conscientização e ressignificação dos papéis e práticas de agentes educacionais, familiares e comunidade escolar; (c) contribuem para o desenvolvimento e/ou a mobilização de competências de todos os envolvidos no processo de escolarização (Marinho-Araujo, 2016).

Esses argumentos têm suas bases em pressupostos do modelo histórico-cultural do desenvolvimento humano, que assume a interação social mediada e a cultura como propulsoras de desenvolvimento humano e do processo de conscientização, derivados da formação de funções psicológicas superiores (Vygotsky, 1986/1996). De acordo com esse modelo, contextos educativos, como é o caso da instituição escolar, são espaços privilegiados para fomento e apropriação, por parte dos sujeitos, de conhecimentos socioculturalmente construídos e organizados, e o psicólogo escolar seria um mediador dos processos e relações que permeiam o cotidiano escolar.

Nessa direção, o presente estudo visou identificar concepções de psicólogos escolares acerca de práticas favorecedoras de aprendizagem e desenvolvimento no contexto escolar. Por concepções, entende-se "crenças elaboradas através de vivências e experiências sociais e culturais ao longo de suas vidas" (Santos, Ramos, \& Salomão, 2015, p. 192), que podem ser acessadas mediante a análise de ideias e expectativas, e que permitem melhor compreensão das ações profissionais e dos elementos que as constituem, tais como crenças culturais, valores coletivos e teorias vigentes. Frente ao exposto, este estudo parte do entendimento de que as concepções de psicólogos escolares acerca de práticas favorecedoras, que têm impacto em suas atuações, são influenciadas pelo perfil de formação de cada profissional.

\section{Método}

Nesta pesquisa, adotou-se uma abordagem qualitativa, por entender-se que tal perspectiva metodológica é adequada a investigações de grupos e segmentos, de histórias sociais sob a ótica dos atores, de relações e análises de discursos e de documentos. Além disso, a referida abordagem é indicada para aprofundar as análises das redes interativas e demandas que constituem os meios educacionais. Sua adoção permite conhecer as experiências, significados, sentidos e vivências dos indivíduos e grupos que participam e constroem o cotidiano escolar e educacional e propicia também a construção de novas abordagens, revisão e criação de conceitos e categorias durante sua realização (Fazenda, 2008; Minayo, 2006; Richardson et al., 2011).

\section{Participantes}

Participaram desta pesquisa 55 psicólogos da rede pública de ensino de um município do Estado da Paraíba, que serão identificados neste artigo com nomes fictícios. No período da realização da pesquisa, eles atuavam em instituições de educação no nível básico pertencentes à Secretaria de Educação. É importante destacar que, na localidade em que o estudo foi realizado, o psicólogo escolar compõe o quadro de profissionais efetivos da rede pública municipal, ingressando nas escolas tanto por meio de concurso público quanto por meio de contratações, cumprindo a carga horária de 20 horas semanais e sendo distribuído nas instituições de acordo com a proporção de um psicólogo para 500 alunos. A faixa etária dos profissionais, que eram predominantemente do sexo feminino $(98,2 \%, n=54)$, variou de 27 a 68 anos $(M=51,48$ anos; $D P=9,97)$, de modo que $49 \%(n=27)$ do total de participantes possuía de 50 a 59 anos; $20 \%(n=11)$ de 41 a $49 ; 18.3 \%(n=10)$ de 60 a 68 anos e 10.9\% $(n=6)$ de 27 a 35 anos. Uma participante optou por não informar a idade, pois considerava essa informação muito pessoal.

\section{Instrumentos}

Questionário sociodemográfico e um roteiro de entrevista semiestruturada (desenvolvido pelas autoras), com nove perguntas abertas acerca de formação, concepções e práticas de psicólogos escolares educacionais, 
sendo uma delas: "Na sua opinião, que práticas do psicólogo escolar podem favorecer processos de desenvolvimento e aprendizagem no contexto escolar?”.

\section{Procedimentos}

A pesquisa foi realizada de acordo com as normas estabelecidas na Resolução nº 466/2012 do Conselho Nacional de Saúde(CNS). Após concedidas as cartas de anuência da Secretaria de Educação e do Comitê de Ética em Pesquisas da Universidade Federal da Paraíba (Protocolo CAAE 35664914.2.0000.5188), teve início o contato com as instituições participantes. Na primeira visita feita a cada instituição, foram explicitados os objetivos do projeto, solicitando-se em seguida a permissão para a realização das entrevistas. Uma vez concedida a autorização, iniciou-se a etapa de entrevistas, realizadas com os psicólogos entre os meses de outubro a dezembro de 2015 em escolas das nove regiões/polos de ensino. A participação na pesquisa estava condicionada a assinatura do Termo de Consentimento Livre e Esclarecido. As entrevistas foram realizadas em locais reservados da instituição, registradas por meio de um gravador de voz e transcritas literalmente para posterior análise.

\section{Análise dos Dados}

As informações obtidas foram analisadas segundo as diretrizes do método de categorização de conteúdo apresentado em Bardin (1977/2008), procedendo-se com a transcrição literal de todo material, seguida de uma leitura flutuante; análise sem categorias pré-fixadas; reunião com o corpo de cinco juízes; e, por fim, organização de eixos de análise. Neste trabalho, foram analisados os relatos dos profissionais participantes a partir de dois eixos de análise, quais sejam: formação para atuar na área escolar e práticas favorecedoras de aprendizagem e desenvolvimento no contexto escolar. Esses eixos são compostos de categorias ou unidades expressas por recortes de falas correspondentes a cada questão a eles dirigida. A essa análise, seguiu-se a discussão dos resultados norteada por pesquisas da Psicologia Escolar, embasadas por uma compreensão histórico-cultural do sujeito e dos processos de desenvolvimento e aprendizagem (Vygotsky, 1931/2012; Vygotsky, Luria, \& Leontiev, 1934/2014).

\section{Resultados e Discussão}

Inicialmente, apresenta-se um panorama da formação dos psicólogos escolares participantes da pesquisa, por compreender que esta possui papel crucial para a construção e/ou ressignificação de concepções de homem, mundo e sociedade (Guzzo, 2011, 2016). Constitui-se, assim, como contexto propício para forjar o compromisso social do psicólogo com o delineamento de práticas favorecedoras de aprendizagem e desenvolvimento no contexto escolar e em outros lócus de atuação em Psicologia. Além disso, como enfatizam Marinho-Araujo e Almeida (2014), no âmbito da formação inicial, podem ser realizadas mediações visando ao desenvolvimento, à mobilização e à redefinição de competências das mais diversas ordens.

Levantou-se que a formação inicial dos participantes foi realizada majoritariamente em uma instituição privada de ensino superior $(52,7 \%, n=29)$, seguida de três instituições públicas também de ensino superior $(47,3 \%, n=26)$. Já o período em que os profissionais entrevistados concluíram o curso de graduação em Psicologia abrange os anos de de 1978 a 2011, assim distribuídos: 47,3\% $(n=26)$ tornaram-se psicólogos na década de $1980 ; 27,3 \%, n=15)$ na década de 1990; $14,5 \%(n=8)$ na década de 2000; e 10,9\% $(n=6)$ na década de 1970. É importante registrar que, até o ano de 2004, os currículos dos cursos de graduação em Psicologia ainda não eram orientados pelas Diretrizes Curriculares Nacionais para os Cursos de Graduação em Psicologia (Brasil, 2004, 2011), que preconizam uma distribuição equânime dos componentes currículares, de modo a contemplar as ênfases de atuação em Psicologia e as demandas do contexto local e regional. Questiona-se, até que ponto, anteriormente a esse período, as instituições formadoras apresentavam em seus currículos uma proposta de formação que contemplasse o trabalho do psicólogo, de modo a favorecer a construção de um perfil profissional que atendesse de forma efetiva às demandas do contexto educativo.

A análise da formação inicial constitui-se um elemento chave para compreender a historicidade e a epistemologia das concepções dos profissionais. Por esse motivo, considerou-se oportuno investigar se, durante a graduação, os participantes tiveram contato com disciplinas da área de Psicologia Escolar. Sobre essa questão, verificou-se que apenas 7,2\% $(n=4)$ dos entrevistados não cursaram tais disciplinas. Embora essa realidade possa indicar um avanço, é necessário refletir sobre que tipo de formação foi ofertada. Nesse sentido, destaca-se a fala "Na época tinha uma, Psicologia Escolar, mas era uma coisa, assim, porque mudou muito o curriculo, né, uma coisa meio superficial mesmo" (Psicóloga Cristina).

Além disso, observou-se que as disciplinas de Psicologia Escolar eram, por vezes, preteridas pelos 
entrevistados, conforme ilustram os discursos "Tinha a cadeira de Psicologia Escolar. (...) Mas, como eu não tinha muita direção pra escola, não fiquei muito atenta, sabe? A gente faz̧ia porque tinha que cumprir" (Psicóloga Cristina); e "Psicologia Escolar I e Psicologia Escolar II. Eram as matérias que, eu digo, sempre tem preconceito (...). Já era estereotipado isso. A galera não ia de jeito nenbum. Todo mundo queria fazer qualquer coisa menos escolar" (Psicóloga Matilde).

Entende-se que esse tipo de concepção sobre a área está diretamente relacionado ao Projeto Político Pedagógico dos cursos de graduação em Psicologia, especialmente no que se refere à área da Psicologia Escolar. Conforme assinala Guzzo (2011), observava-se um cenário onde as disciplinas ofertadas eram reduzidas a áreas específicas do saber psicológico e cursadas, pelos alunos, de modo eletivo, o que teria gerado um contato superficial com o campo escolar. Nesse sentido, é importante destacar ainda que 20\% $(n=11)$ dos psicólogos entrevistados, além do curso de formação em Psicologia, concluíram a habilitação licenciatura, o que pode indicar maior aprofundamento acerca das temáticas da interface existente nos campos da Psicologia e da Educação. Nesse sentido, cabe resgatar falas como: "Tinha (...) porque, na verdade, meu curso foi de licenciatura, né (...) A gente teve várias disciplinas que eram voltadas pra esse, pra esse campo educacional. (...) A formação, em si, ela épredominantemente clinica, nê" (Psicóloga Ana).

Foram investigadas ainda as áreas em que os participantes realizaram estágio supervisionado. A menção mais frequente indicou o estágio em Psicologia Escolar $(48,4 \%, n=26)$, seguido de Psicologia Clínica (40\%, $n=$ 22), Psicologia Organizacional $(3,4 \%, n=2)$, Psicomotricidade $(3,4 \%, n=2)$, Psicologia do Trânsito $(1,6 \%$, $n=1)$, Psicologia Hospitalar $(1,6 \%, n=1)$ e Psicologia Jurídica $(1,6 \%, n=1)$. Essa diversidade na prática de estágio supervisionado pode gerar dificuldades no exercício profissional, em razão das especificidades do trabalho do psicólogo no âmbito da educação.

Nessa linha de raciocínio, afirma-se, em consonância com Silva Neto e Guzzo (2016), que a prática de estágio supervisionado no contexto pretendido de trabalho e a formação a ela atrelada têm impacto direto nas ações desenvolvidas pelos psicólogos. Ainda segundo os autores, o estágio supervisionado curricular em Psicologia Escolar é influenciado por fatores como: o perfil acadêmico e profissional do supervisor na área da Psicologia Escolar e em áreas afins; os referenciais teórico-metodológicos que norteiam a supervisão e as ações dos estagiários na escola; o período e o tempo dedicados à supervisão, bem como o número de estagiários para cada supervisor, dentre outros aspectos. Dessa forma, os entraves na atuação de profissionais que não tiveram experiência de estágio supervisionado em Psicologia Escolar podem ser reflexo de desencontros entre a área de formação básica e a atividade profissional (Borges-Andrade et al., 2015.)

Como a maioria dos participantes realizou estágio supervisionado em áreas diversas à Psicologia Escolar, considerou-se pertinente investigar se o estágio nessa área era ofertado. A maioria dos profissionais $(65,5 \%, n$ = 36) relatou que havia estágio em Psicologia Escolar, $23 \%(n=13)$ informaram que não sabiam e 11,5\% $(n=$ 6) declararam que não era disponibilizado esse tipo de estágio. Ilustra esse conjunto de informações, a seguinte fala: "Olhe, pra dizer a verdade, eu não estou muito lembrada não (...). As pessoas corriam muito para a formação clínica. Para a formação escolar, não, era menos gente, era menos interesse, entende?" (Psicóloga Dalva). Conclui-se que, embora, durante a graduação, os profissionais entrevistados tenham preterido a Psicologia Escolar como campo de atuação, eles passaram a trabalhar nesse âmbito por razões como emprego/aprovação em concurso, como indicam as falas: "Mas, de fato, o que me levou (a atuar na área escolar) foi passar num concurso, né. Provavelmente, se en não tivesse passado, eu não teria entrado nessa área" (Psicólogo José); e "Eu entrei de gaiata no navio, porque minha paixão mesmo é clínica, mas, como eu ganhei esse emprego da Prefeitura, mudou" (Psicóloga Cristina). Dentre as implicações que isso pode ter para a atuação, menciona o risco de uma concepção distorcida do papel do psicólogo escolar, bem como insatisfação ao se deparar com as demandas e exigências da prática no contexto escolar.

$\mathrm{Na}$ análise crítica realizada por Borges-Andrade et al. (2015) acerca do desenvolvimento da profissão da Psicologia no contexto brasileiro, eles observaram que um terço dos psicólogos não trabalha com o campo para o qual foi formado e um quarto atuam em conjunto com outras atividades laborais. Esse tipo de realidade tem repercussões para toda a comunidade escolar, já que o trabalho do psicólogo na educação está relacionado à promoção de desenvolvimento, ao fomento à aprendizagem e à mediação de processos de conscientização dos atores daquele contexto.

Tomando-se por base essas informações, considera-se pertinente refletir acerca de como a diversidade na formação dos participantes deste estudo interfere nos modos de trabalho, nas inquietações por buscas de formações continuadas e nas possíveis contribuições dessas formações. Diante desses resultados buscou-se conhecer, dentre outros aspectos, o que os psicólogos 
entrevistados consideravam como práticas favorecedoras de aprendizagem e desenvolvimento no contexto escolar. Os resultados da análise desta questão estão sintetizados na Figura 1.

A Figura 1 exibe as práticas consideradas, pelos psicólogos escolares, como favorecedoras de aprendizagem e desenvolvimento no contexto escolar, quais sejam: intervir com os alunos $(n=19)$, intervir nas relações $(n=12)$, intervir com os pais $(\mathrm{n}=7)$, intervir no âmbito pedagógico $(n=9)$ e intervir com os agentes escolares $(n=8)$. Os resultados dos relatos desses profissionais encontram-se em consonância com o estudo de Campos e Jucá (2003). Para eles, dentre as funções que o psicólogo escolar deveria desempenhar na instituição, destacam-se acompanhar os alunos, intervir nas relações escolares, apoiar o processo de ensino-aprendizagem e promover uma maior relação entre a família e a escola.

A categoria intervir com os alunos é exemplificada por falas como “(...) burilando as crianças que tão em formação, que tão em desenvolvimento (...) proporcionando a eles que eles se tornem criancas mais calmas, mais atenciosas, mais concentradas (...). Você melhora no comportamento e, consequentemente, você vai perceber que, na aprendizagem, ele vai estar mais conectado" (Psicóloga Vanda). Observou-se, nos discursos que compuseram essa categoria, a menção a características individuais e comportamentais dos alunos como obstáculos ao processo de ensino-aprendizagem. Tais falas partem da ideia de que o bom aluno é aquele que se mantém calado, a despeito da compreensão mais interacionista da criança e da aprendizagem. Nesse sentido, defende-se a perspectiva vygotskyana segundo a qual é a interação social que promove o desenvolvimento humano e os processos de aprendizagem, uma vez que é por meio dessa interação que as funções psicológicas se reorganizam qualitativamente e que o indivíduo aprende, organiza e ressignifica sua relação com $\mathrm{O}$ contexto sociocultural em que se encontra (Marinho-Araujo \& Almeida, 2010; Moreira e Guzzo, 2014; Souza, Petroni, Dugnani, Barbosa, \& Andrada, 2014; Vygotsky, 1986/1996).

Nessa categoria, incluem-se práticas de aconselhamento ou de atendimento, como se observa nos discursos "A gente faz o serviço de aconselhamento" (Psicóloga Paula) e "Aqui en utilizo muito a psicoterapia breve focal, dentro da escola, sabe. Eu acho muito rico assim. Eu acho que a visão, quando você é psicólogo escolar e você tem a clinica. Eu acho que amplia muito, assim, nossas possibilidades" (Psicóloga Verônica). Verificou-se também que alguns profissionais consideram que suas práticas não são clínicas porque, embora se utilizem de recursos e técnicas dessa área da Psicologia, o fazem por um curto período de tempo. Ilustram essa percepção falas como "Às vezes, en faço um acompanhamentozinho breve, mas tendo esse cuidado de saber que a clínica tem toda uma questão especifica, todo um cuidado específico, e educacional é diferente e isso ainda não é claro na mente das pessoas (...). É basicamente isso, é um acompanhamento individual breve, porque não é atendimento clínico, nê" (Psicóloga Lourdes). Por fim, uma entrevistada defendeu a presença de psicólogos clínicos na escola: "É muito difícil, na prática (...) A gente não ter essa escuta desse aluno que chega chorando, desse aluno que chega aéreo, muitos problemas em casa, né, que não conseguem assistir aula. Eu inclusive sou muito a favor que existisse, assim, uma salinha (...) pra se ter esse atendimento, mesmo que fosse até outro psicólogo, clínico, vindo pra escola, entendeu?" (Psicóloga Verônica).

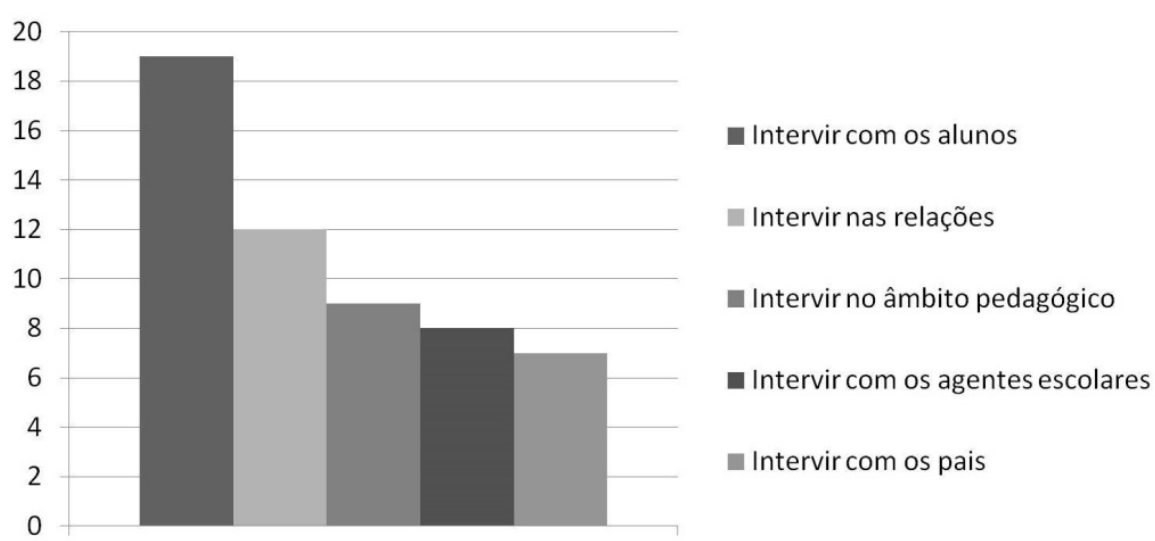

Figura 1. Práticas consideradas, pelos psicólogos escolares, como favorecedoras de aprendizagem e desenvolvimento no contexto escolar. 
Esses relatos sugerem que parte dos profissionais parece não compreender claramente os limites que separam a atuação em contextos clínicos daquela em contextos escolares. Destaca-se ainda que a escuta psicológica consiste em uma das ações que demarcam a especificidade do trabalho desse profissional na escola. Contudo, adverte-se para que essa escuta seja desenvolvida em uma perspectiva institucional, de modo a permitir a apreensão de sentidos, significados e contradições úteis para compreender a dinâmica escolar e nela intervir (Marinho-Araujo, 2014). A questão que se discute não se refere apenas à realização de práticas clínicas na escola, mas de que, no contexto escolar, as práticas institucionais, relacionais e preventivas possuem maior potência para transformar a realidade. Nesse aspecto, é importante que o psicólogo escolar esteja atento a seu perfil profissional e às suas funções e que, no momento de sua inserção na escola, apresente-as à comunidade escolar e discuta suas possibilidades de intervenção pautadas nas demandas de cada contexto.

O psicólogo escolar deve estar ciente das especificidades de sua atuação. A esse respeito, destaca-se o risco que representam (in)compreensões como " $\mathrm{E} u$ digo aqui que todo mundo é um pouco de psicólogo, porque na escola você faz tudo, nê" (Psicóloga Marta) e "Aqui na escola, se houver necessidade, eu atuo em outras áreas também, não necessariamente só na área de Psicologia, entendeu?" (Psicóloga Eveline). Atuar, no interior da escola, em outros campos que não o da Psicologia pode gerar implicações tais como a perda da especificidade da profissão (Marinho-Araujo \& Almeida, 2014). Pode também revelar tanto um desconhecimento, por parte desse profissional, das possibilidades e especificidades de sua atuação, além da falta de motivação para o trabalho em um contexto escolar. Alerta-se, portanto, para o fato de que a identidade do psicólogo escolar e a especificidade que a delimita devem ser construídas desde a graduação em Psicologia e fortalecidas no estágio supervisionado curricular e em pesquisas realizadas durante a graduação e a pós-graduação.

Já a categoria intervir nas relações engloba discursos como "Trabalhar a questão do relacionamento interpessoal entre eles, não é, entre os pares, entre os alunos e professores" (Psicóloga Maria) e "Olhe, eu acho que a escola, assim, ela tem uma série de, de, de grupos, de relações de poder, que o psicólogo deveria entrar aí. Eu não faço isso, não é minha prática, mas teria que entrar" (Psicóloga Antônia). A respeito dessa categoria, destaca-se a importância da atuação do psicólogo escolar no sentido de resgatar a afetividade nas relações, nomeadamente a relação professor-aluno, como via de potencializar processos de desenvolvimento e aprendizagem (Galdini \& Aguiar, 2003; Souza et al., 2014; Marinho-Araujo, 2014).

A categoria intervir com os pais, por sua vez, está representada em relatos como: “(...) com a família $e$ é nesse contexto que se tira algum proveito porque você vai conscientizar a família de como reagir com seus filhos, de como trabalhar, como orientar, para que os seus filhos tenham um comportamento mais coerente com a realidade escolar" (Psicóloga Helena). Cabe, no entanto, questionar o modo como os pais são convocados a comparecer à escola, uma vez que predominaram relatos de práticas indicando a culpabilização da família em relação a padrões comportamentais dos alunos ou a dificuldades no processo de escolarização. Por outro lado, considera-se que existem práticas, como convocar os pais para tratar de temas do interesse deles, que favorecem uma relação mais profícua entre família e escola.

Já a prática de intervir no âmbito pedagógico, foi mencionada em discursos como "Eu acho que se envolver nessa questão pedagógica favorece. Pedagógica no sentido do professor em sala de aula, do manejo de algumas situações e a questão metodológica realmente. Porque, muitas vezes, aquela metodologia não está adequada pra faixa etária, ou não tá adequada praquele público que tá ali, nê" (Psicólogo José) e "Pode ajudar também no sentido de dar um suporte em relação a conhecimentos do desenvolvimento mesmo, né, do processo de aprendizagem, do desenvolvimento de forma geral, das relaçoes em determinadas idades" (Psicólogo José). Nesse sentido, enfatiza-se o risco de lançar mão dos conhecimentos psicológicos para explicar os processos de desenvolvimento e aprendizagem com base em supostos padrões de normalidade (Guzzo, 2011, 2016; Moreira \& Guzzo, 2014). Destaca-se a importância de utilizá-los no sentido de entender e conscientizar acerca da complexidade do processo de ensino-aprendizagem e da existência de vários ritmos e formas de aprender.

Por fim, a categoria intervir com agentes escolares está evidenciada em discursos como "A prática junto com os colegas da equipe para que eles não trabalhem isolados em sala de aula (...) pra que a gente possa dar algumas orientações e que a gente some com eles" (Psicóloga Daiane). A respeito desse tipo de intervenção do psicólogo escolar, Barbosa (2008) sugere que o profissional desenvolva práticas que envolvam: reflexões acerca da atuação e dos conhecimentos teóricos necessários para atuar no contexto escolar; criação de espaços onde os agentes escolares possam compartilhar experiências, compreensões e reflexões; promoção da circulação de sentidos e 
significados; e o desenvolvimento de habilidades interpessoais como a colaboração e a assertividade.

Outros pesquisadores (Galdini \& Aguiar, 2003; Marinho-Araujo \& Almeida, 2010) evidenciam que o psicólogo escolar deve investigar e analisar, junto aos agentes escolares, a dinâmica da instituição, as contradições entre as demandas efetivas e as intervenções desenvolvidas, contribuindo para um redirecionamento das práticas profissionais por meio de rupturas ou reformulações institucionais. Cabe ao psicólogo escolar criar espaços de interlocução com todos os agentes escolares, a fim de trabalhar os aspectos objetivos e subjetivos que perpassam os processos de desenvolvimento e de aprendizagem e de promover reflexões que levem a uma emancipação dos referidos agentes, no sentido de que eles passem, de modo autônomo, mas não isolado, a trabalhar em prol da potencialização dos referidos processos (Facci, 2015; Oliveira \& Marinho-Araujo, 2009).

Para além das práticas favorecedoras de aprendizagem e desenvolvimento apontadas com maior frequência pelos participantes (intervir com os alunos, intervir nas relações, intervir com os pais, intervir no âmbito pedagógico e intervir com os agentes escolares), com menor frequência, foram consideradas práticas favorecedoras de aprendizagem e desenvolvimento no contexto escolar: Intervenções com alunos, familiares e professores; elaboração e execução de projetos; integração entre a equipe de especialistas e as famílias; considerar o contexto e não culpabilizar o aluno e a família; providenciar diagnóstico e encaminhamento; intervenções com professores e familiares; motivar alunos e familiares; realizar escuta e orientação de professores e alunos; fortalecer a escola e os profissionais; realizar trabalho preventivo. Menciona-se ainda as falas: "estar na escola de mãos dadas" e "estar atento a tudo", que, embora expressem ideias mais abrangentes, podem constituir-se em indicadores de um olhar mais ampliado acerca do papel do psicólogo na escola.

Do exposto, verifica-se que ainda há um descompasso entre a formação e a prática profissional no âmbito da Psicologia Escolar. Por isso, reafirma-se a importância de que, tanto na graduação quanto em momentos de formação continuada, a articulação entre teoria e prática seja ponto norteador do planejamento curricular e dos momentos e estratégias metodológicas de ensino e aprendizagem. Assim, assegurar-se-ia o desenvolvimento e a mobilização de competências, que devem ser avaliadas pelo psicólogo escolar constantemente ao longo de sua carreira, visando uma identidade profissional dinâmica e condizente com os múltiplos, diversos e cambiantes desafios e demandas da realidade escolar.

A partir dessa (re)construção da identidade profissional, o psicólogo escolar construiria uma leitura mais crítica e reflexiva sobre seu trabalho e sobre a globalidade dos processos de desenvolvimento e aprendizagem que deve mediar, passando a ter consciência das transformações que pode promover no contexto escolar e nas relações nele estabelecidas em prol da construção de situações sociais de desenvolvimento para todos os envolvidos no processo de escolarização: estudantes, pais/responsáveis, agentes escolares (Vygotsky, 1931/2012, 1982/2012; Vygotsky, Luria, \& Leontiev, 1934/2014).

\section{Considerações Finais}

Este estudo objetivou identificar concepções de psicólogos escolares acerca de práticas favorecedoras de aprendizagem e desenvolvimento no contexto escolar, questão analisada levando em conta o perfil de formação dos participantes, dada a estreita relação entre este e as práticas profissionais. De maneira geral, percebeu-se que os participantes da pesquisa possuíam um perfil de formação que se refletiu em suas concepções acerca de quais práticas seriam favorecedoras de aprendizagem e desenvolvimento no contexto escolar. $\mathrm{A}$ análise desses resultados conduziu à reflexão sobre o tipo de formação disponibilizada pelas instituições de ensino superior nos períodos em que os participantes realizaram seus cursos de graduação, destacadamente no que diz respeito às modalidades de formação e à existência ou não de momentos intencionalmente planejados para articulação entre teoria e prática, como os estágios supervisionados curriculares.

No que se refere às práticas relatadas como favorecedoras, as falas dos profissionais se concentraram em intervenções junto a alunos, pais e professores, por meio de ações técnico-pedagógicas e de suporte emocional. Conforme se observou, as respostas a essa questão se voltaram para ações que têm sido defendidas como focos de intervenção do psicólogo escolar que potencializam e promovem o desenvolvimento do coletivo da instituição. No entanto, é importante ressaltar que, embora os profissionais tenham mencionado ações junto aos alunos, aos professores e aos pais, devese ter a compreensão de que a unidade de análise que sustentará o trabalho do profissional de psicologia na escola é a relação entre os atores institucionais, e não 
o trabalho isolado, setorizado, particularizado (Marinho -Araujo, 2014).

Observou-se a emergência, mesmo que tímidas, de novas formas de atuação em Psicologia Escolar, destacando-se, nesse sentido, intervenções voltadas às relações escolares, aos aspectos pedagógicos e às práticas de agentes escolares. Os relatos dos participantes sobre essas práticas indicam que eles se encontram em transição para um novo paradigma de Psicologia Escolar, caracterizado por ações institucionais, preventivas e relacionais. Ou seja, embora ainda tenham sido apresentados relatos de práticas marcadamente individualizantes, verificou-se, por meio da análise das falas, que estas vêm sendo tensionadas pelo contato com novos conhecimentos ou por se mostrarem pouco eficazes para transformar a realidade escolar. Essa ideia ganha apoio com os estudos de Moreira (2015) e Moreira e Guzzo (2014), para quem, embora historicamente a Psicologia tenha sido definida e representada como ciência da cura, o reconhecimento e a crítica desse modelo de atuação e das concepções que o embasam abriram possibilidades para tensioná-lo e combatê-lo.

Como limitação do presente estudo, mencionase o fato de que não foram investigadas também as concepções de psicólogos escolares da rede privada de ensino acerca de práticas favorecedoras de aprendizagem e desenvolvimento no contexto escolar. Além disso, considera-se que a realização de observações sistemáticas e interativas (Marinho-Araujo \& Almeida, 2014) das práticas dos profissionais entrevistados, bem como a condução de entrevistas com agentes escolares que atuam junto a eles, teriam contribuído para identificar, para além das informações socializadas no momento de entrevista, como as práticas favorecedoras referidas pelos psicólogos escolares se concretizam em seus contextos de atuação.

Dessa forma, considera-se importante que, em investigações futuras, para além de apreender concepções expressas em discursos, busque-se conhecer o cotidiano dos psicólogos escolares e, assim, produzir um material que expresse a concretude vivenciada por esses sujeitos em suas práticas. Além disso, é importante enfatizar que, no contexto de realização da pesquisa, a partir de 2015, houve alterações no quadro de psicólogos escolares devido à efetivação, após concurso público, de novos psicólogos escolares na rede pública de ensino. Nesse sentido, é fundamental assegurar a continuidade de pesquisas a fim de acompanhar as transformações na realidade investigada. Por isso, sugere-se o desenvolvimento de propostas de extensão ou ainda de pesquisa-intervenção, em nível de graduação e/ou pós-graduação, que possam contribuir teórica e metodologicamente para as práticas dos referidos profissionais, na perspectiva de ressignificar os cenários e o cotidiano nos quais estão inseridos. Além disso, o campo de pesquisa pode ser ampliado na direção de escolas de ensino médio, técnico e superior, já que se constituem campos emergentes de atuação do psicólogo (Marinho-Araujo, 2010).

Por fim, defende-se o estreitamento das relações entre universidades e escolas públicas, bem como a parceria entre essas instâncias, na perspectiva de mobilizar ações de psicólogos com formação em Psicologia Escolar, para que possam atender às necessidades e complexidades da escola pública brasileira e para que as práticas psicológicas em contextos de educação sejam respostas que promovam aprendizagem e desenvolvimento, contribuindo, dessa forma, para resgatar a função social da escola.

\section{Referências}

Antunes, M. A. M. (2011). Psicologia e Educação no Brasil: Uma análise história. Em R. G. Azzi \& M. H. T. A. Gianfaldoni (Eds.), Psicologia e Educação (pp. 9-32). São Paulo: Casa do Psicólogo.

Barbosa, D. R. (2012). Contribuições para a construção da historiografia da Psicologia Educacional e Escolar no Brasil. Psicologia: ciência e profissão, 32(número especial), 104-123. doi: 10.1590/S1414-98932012000500008

Barbosa, R. M. (2008). Psicologia Escolar nas Equipes de Atendimento/Apoio à Aprendizagem de Samambaial DF: Atuação institucional a partir da abordagem por competências (Dissertação de mestrado não publicada). Universidade de Brasília, Brasilia.

Barbosa, R. M., \& Marinho-Araujo, C. M. (2010). Psicologia Escolar no Brasil: Considerações e reflexões históricas. Estudos de Psicologia, 27(3), 394-402. doi: 10.1590/S0103-166X2010000300011

Bardin, L. (2008). Análise de conteúdo. Lisboa: Edições 70. (Original publicado em 1977).

Borges-Andrade, J. E., Bastos, A. V. B., Andery, M. A. P. A., Guzzo, R. S. L., \& Trindade, Z. A. (2015). Psicologia Brasileira: Uma análise de seu desenvolvimento. Universitas Psychologica, 14(3), 865-880. doi: 10.11144/Javeriana.upsy14-3.pbua 
Campos, H. R., \& Jucá, M. R. B. L. (2003). O psicólogo na escola: Avaliação da formação à luz das demandas do mercado. Em S. F. C. de Almeida (Ed.), Psicologia Escolar: Ética e competências na formação e atuação profissional (pp. 37-56). Campinas: Alínea.

Cavalcante, L. A., \& Aquino, F. S. B. (2013). Ações de psicólogos escolares de João Pessoa sobre queixas escolares. Psicologia em Estudo, 18(2), 353-362. doi: 10.1590/S1413-73722013000200016

Fazenda, I. C. A. (2008). O que é interdisciplinaridade? São Paulo: Cortez.

Galdini, V., \& Aguiar, W. M. J. (2003). Intervenção junto a professores da rede pública: Potencializando a produção de novos sentidos. Em M. E. M. \& M. A. M. Antunes (Eds.), Psicologia escolar: Práticas críticas (pp. 87-103). São Paulo: Casa do Psicólogo.

Guzzo, R. S. L. (2002). Novo paradigma para a formação e atuação do psicólogo escolar no cenário educacional brasileiro. Em R. S. L. Guzzo (Ed.), Psicologia Escolar: LDB e educação hoje (pp. 131-144). Campinas: Alínea.

Guzzo, R. S. L. (2008a). Formando psicólogos escolares no Brasil: Dificuldades e perspectivas. In: S. M. Wechsler (Ed.), Psicologia Escolar: Pesquisa, formação e prática (pp. 75-92). Campinas: Alínea.

Guzzo, R. S. L. (2008b). Psicologia em instituições escolares e educativas: Apontamentos para um debate. Em Conselho Federal de Psicologia (Ed.), Ano da Psicologia na Educaşão: Textos geradores (pp. 5362). Brasília: CFP.

Guzzo, R. S. L. (2010). Educação para a liberdade, psicologia da libertação e psicologia escolar: Uma práxis para a liberdade. Em S. F. C de Almeida (Ed.), Psicologia escolar: Ética e competências na formação e atuação profissional. (pp. 169- 177). Campinas: Alínea.

Guzzo, R. S. L. (2011). Desafios cotidianos em contextos educativos: A difícil formação de psicólogos para a realidade brasileira. Em R. G. Azzi \& M. H. T. A. Gianfaldoni (Eds.), Psicologia e Educação (pp. 253-270). São Paulo: Casa do Psicólogo.

Guzzo, R. S. L. (2016). Desafios para o cotidiano do psicólogo dentro da escola: A questão do método. Em M. V. Dazzani \& V. L. T. de Souza, Psicologia Escolar crítica: Teoria e prática nos contextos educacionais (pp. 21-35). Campinas: Alínea.

Guzzo, R. S. L., Mezzalira, A. S. C., Moreira, A. P. G., Tizzei, R. P., \& Neto, W. M. F. S. (2010). Psicologia e Educação no Brasil: Uma visão da história e possibilidades nessa relação. Psicologia Teoria e Pesquisa, 26(número especial), 131-141. doi: 10.1590/ S0102-37722010000500012

Maluf, M. R., \& Cruces, A. V. V. (2008). Psicologia educacional na contemporaneidade. Boletim Academia Paulista de Psicologia, 28(1), 87-99. Recuperado de http://pepsic.bvsalud.org/scielo. php?pid $=$ S1415-711X2008000100011\&script $=$ sci_arttext\&tlng $=$ es

Marinho-Araujo, C. M. (2014). Intervenção institucional: Ampliação crítica e política da atuação em psicologia escolar. Em R. S. L. Guzzo (Ed.), Bastidores da escola e desafios da educaşão pública: A pesquisa e a prática em psicologia escolar (pp. 153-175). Campinas: Alínea.

Marinho-Araujo, C. M. (2010). Psicologia Escolar: Pesquisa e intervenção. Em aberto, 23(83), 17-35. Recuperado de http://emaberto.inep.gov.br/index.php/emaberto/article/view/2249

Marinho-Araujo, C. M. M., \& Almeida, S. F. C. (2010). Psicologia Escolar Institucional: Desenvolvendo competências para uma atuação relacional. Em S. F. C. Almeida (Ed.), Psicologia escolar: Ética e competências na formação e atuação profissional (pp. 59-82). Campinas: Alínea.

Marinho-Araujo, C. M. M., \& Almeida, S. F. C. (2014). Psicologia escolar: Construção e consolidação da identidade profissional. Campinas: Alínea.

Marinho-Araujo, C. M., \& Neves, M. M. B. J. (2007). Psicologia escolar e a formação continuada em serviço: Encurtando distâncias entre teorias e práticas. Boletim Academia Paulista de Psicologia, 27(1), 56-71. Recuperado de http://pepsic. bvsalud.org/scielo.php?script=sci_arttext\&pid=S1415-711X2007000100011

Martínez, A. M. (2010). O que pode fazer o psicólogo na escola? Em Aberto, 23(83), 39-56. Recuperado de http://repositorio.unb.br/handle/10482/6292

Mendes, A. C. M. (2011). Oficina lúdica e mediação estética na formação continuada de psicólogos escolares (Dissertação de mestrado não publicada). Universidade de Brasília, Brasília.

Minayo, M. C. S. (2006). O desafio do conhecimento: Pesquisa qualitativa em saúde. São Paulo: Hucitec.

Ministério da Educação e Cultura (2004). Diretrizes curriculares nacionais para os cursos de graduação em psicologia. Brasília, DF: MEC. 
Ministério da Educação e Cultura (2011). Diretrizes curriculares nacionais para os cursos de graduação em psicologia. Brasília: DF: MEC.

Moreira, A. P. G. (2015). Situação-limite e potência de ação: Atuação preventiva crítica em psicologia escolar (Tese de doutorado não publicada). Pontifícia Universidade Católica de Campinas, Campinas.

Moreira, A. P. G., \& Guzzo, R. S. L. (2014). A psicologia que defendemos na escola que vivemos: Uma contribuição dos bastidores do "Voo da Águia". Em R. S. L. Guzzo (Ed.), Psicologia escolar: Desafios e bastidores da educação pública (pp. 13-26). Campinas: Alínea.

Neves, M. M. B. J. (2009). A atuação dos psicólogos escolares no Distrito Federal. Em C. M. Marinho-Araujo (Ed.), Psicologia escolar: Novos cenários e contextos de pesquisa, formação e prática (pp. 55-73). Campinas: Alínea.

Neves, M. M. B. J. (2011). Queixas escolares: Conceituação, discussão e modelo de atuação. Em C. M. Marinho-Araujo (Ed.), Psicologia escolar: Identificando e superando barreiras (pp. 175-214). Campinas: Alínea.

Neto, W. M. S. F., \& Guzzo, R. S. L. (2016). Internship in school psychology: Education and practice of the supervisor. Estudos de Psicologia (Campinas), 33(2), 213-224. doi: 10.1590/1982-02752016000200004

Nunes, L. L., Alves, S. S., Ramalho, J. V., \& Braz Aquino, F. S. (2014). Contribuições da perspectiva crítica de base histórico-cultural para a produção científica em psicologia educacional. Educação e Pesquisa, 40(3), 667-682. doi: 10.1590/s1517-97022014091471

Oliveira, C. B. E. de, \& Marinho-Araujo, C. M. (2009). Psicologia Escolar: Cenários atuais. Estudos e pesquisas em Psicologia, 9(3), 648-663. Recuperado de http://www.e-publicacoes.uerj.br/index.php/ revispsi/article/view/9075/7475

Patto, M. H. S. (1981). Prefácio. Em M. H. S. Patto (Ed.), Introdução à Psicologia Escolar (pp. 1-4). São Paulo: T. A. Queiroz.

Patto, M. H. S. (1997). Para uma crítica da razão psicométrica. Psicologia USP, 8(1), 47-62. doi: 10.1590/ S0103-65641997000100004.

Richardson, R. J., Peres, J. A. S., Wanderley, J. C. V., Correia, L. M., \& Peres, M. H. M. (2011). Pesquisa social: Métodos e técnicas. São Paulo: Atlas.
Rossi, T. M. F., \& Paixão, D. L. L. (2003). Significações sobre a atuação do psicólogo escolar. In: S. F. C. Almeida (Ed.), Psicologia escolar: Ética e competências na formação e atuação profissional (pp. 147-166). Campinas: Alínea.

Santos, E. R. F., Ramos, D. D., \& Salomão, N. M. R. (2015). Concepções sobre desenvolvimento infantil na perspectiva de educadoras em creches públicas e particulares. Revista Portuguesa de Educação, 28(2), 189-209. Recuperado de http://www. scielo.mec.pt/scielo.php?script $=$ sci_arttext\&pi$\mathrm{d}=$ S0871-91872015000200010

Souza, M. P. R. (2011). Retornando à patologia para justificar a não aprendizagem escolar: a medicalização e o diagnóstico de transtornos de aprendizagem em tempos de neoliberalismo. Em Conselho Regional de Psicologia de São Paulo (Ed.), Medicalização de crianças e adolescentes: Conflitos silenciados pela redução de questões sociais a doença de indivíduos (pp. 57-67). São Paulo: Casa do Psicólogo.

Souza, V. L. T., Petroni, A. P., \& Dugnani, L. A. C. (2011). A arte como mediação nas pesquisas e intervenção em Psicologia Escolar. Em R. S. L. Guzzo \& C. M. Marinho-Araujo (Eds.), Psicologia escolar: Identificando e superando barreiras (pp. 261285). Campinas: Alínea.

Souza, V. L. T., Petroni, A. P., Dugnani, L. A. C., Barbosa, E. T., \& Andrada, P. C. (2014). O psicólogo na escola e com a escola: A parceria como forma de atuação promotora de mudanças. Em R. S. L. Guzzo (Ed.), Psicologia escolar: Desafios e bastidores da educação pública (pp. 27-54). Campinas: Alínea.

Vygotsky, L. S. (2012a). Historia del desarrollo de las funciones psiquicas superiores: Obras escogidas, Tomo III. Madrid: Machado Libros. (Original publicado em 1931).

Vygotsky, L. S. (2012b). El significado bistórico de la crise de la Psicología: Obras escogidas, Tomo I. Madrid: Machado Libros. (Original publicado em 1982).

Vygotsky, L. S. (1996). Teoria e método em Psicologia. São Paulo: Martins Fontes. (Original publicado em 1986).

Vygotsky, L. S., Luria, A. R., \& Leontiev, A. N. (2014). Linguagem, desenvolvimento e aprendizagem. São Paulo: Ícone. (Original publicado em 1934).

Recebido em: 25/01/2017 Reformulado em: 10/03/2018

Aprovado em: 15/05/2018 
Sobre as autoras:

Lorena de Almeida Cavalcante é doutoranda em Processos de Desenvolvimento Humano e Saúde na Universidade de Brasília (PGPDS-UnB) e mestre em Psicologia Social pela Universidade Federal da Paraíba (PPGPS-UFPB); possui experiência nas áreas de Psicologia Escolar e Psicologia do Desenvolvimento Humano e compõe, atualmente, o GT de Psicologia Escolar Educacional da ANPEPP.

ORCID: 0000-0002-2330-829X

E-mail: lorenacavalcante@uol.com.br

Fabíola de Sousa Braz Aquino é professora do Departamento de Psicologia e do Programa de Pós-Graduação em Psicologia Social da Universidade Federal da Paraíba, realiza pesquisas nas áreas da Psicologia do Desenvolvimento Infantil, Educação Infantil e Psicologia Escolar e Educacional, supervisora de estágio no campo da Psicologia Escolar, em contextos públicos de educação e membro do GT de Psicologia Escolar e Educacional da ANPEPP. Nome em citações bibliográficas: Braz Aquino, F. de S.

ORCID: 0000-0002-8854-8577

E-mail: fabiolabrazaquino@cchla.ufpb.br

E-mail alternativo: fabiolabrazaquino@gmail.com

Contato com as autoras:

QMSW 06, Lote 02, Bloco C, apartamento 102, Edifício Espaço Villa Verde, Setor Sudoeste Brasília-DF, Brasil

CEP: 70680-600 